\title{
Optical inspection methods and their applications in the manufactured industrial sector: knowledge transfer to Panamanian industry
}

\section{Abdiel Pino, Josep Pladellorens}

Abdiel O. Pino, Josep Pladellorens, "Optical inspection methods and their applications in the manufactured industrial sector: knowledge transfer to Panamanian industry," Proc. SPIE 9289, 12th Education and Training in Optics and Photonics Conference, 928927 (17 July 2014); doi: 10.1117/12.2070724

Event: 12th Education and Training in Optics and Photonics Conference, 2013, Porto, Portugal 


\title{
Optical inspection methods and their applications in the manufactured industrial sector: Knowledge transfer to Panamanian industry
}

\author{
Abdiel O. Pino [1], Josep Pladellorens [2] \\ [1] Natural Sciences Department, Technological University of Panama \\ Technological University of Panama Avenue, Betania, Panama, abdiel.pino@utp.ac.pa \\ [2] CD6 Optics and Optometry Department, Polytechnic University of Catalonia \\ Rambla de Sant Nebridi 10, Terrassa, Spain 08222, pladellorens@oo.upc.edu
}

\begin{abstract}
A means of facilitating the transfer of Optical inspection methods knowledge and skills from academic institutions and their research partners into Panama optics and optical research groups is described. The process involves the creation of an Integrated Knowledge Group Research (IKGR), a partnership led by Polytechnic University of Panama with the support of the SENACYT and Optics and Optometry Department, Polytechnic University of Catalonia. This paper describes the development of the Project for knowledge transfer "Implementation of a method of optical inspection of low cost for improving the surface quality of rolled material of metallic and nonmetallic industrial use", this project will develop a method for measuring the surface quality using texture analysis speckle pattern formed on the surface to be characterized. The project is designed to address the shortage of key skills in the field of precision engineering for optical applications. The main issues encountered during the development of the knowledge transfer teaching and learning are discussed, and the outcomes from the first four months of knowledge transfer activities are described. In overall summary, the results demonstrate how the Integrated Knowledge Group Research and new approach to knowledge transfer has been effective in addressing the engineering skills gap in precision optics for manufactured industrial sector.
\end{abstract}

Keywords: Knowledge Transfer, optical inspection, speckle, texture, industrial sectors, surface quality.

\section{INTRODUCTION}

Processes experienced changes in the world economy in the last 20 years have affected the developing countries, with negative effects on their economies due to low scientific and technological level they possess. Panama, as a member country of the sector, does not escape this great reality, with great limitations on high technology, confront serious difficulties to undertake projects and programs within the activities for the development of industrial sector. One of the most important aspects to watch in the industry in Panama, is the lack of funds for investment in research and development projects. The experience of the industrial sectors of developed countries around new or improved products is that their production, are supported by high investments in research projects that aim, bring to market these new or improved products. That is, creating new knowledge from which new applications arise in the industry.

\subsection{Research and Development in Panama}

In the survey data indicated in research, development and innovation in the private sector in Panama, 52.9\% of the industries reported investigations and within these, 54.1\% have units responsible for conducting research and development activities, but there a difference of opinion on the part of industry, the research concept. Industries that reported doing some research, only $18.2 \%$ make investments in research projects aimed to produce new or significantly improved. Industries according to the declared type of research, we note that the $4.41 \%$ perform basic research, applied and experimental $6.35 \%$ conducts applied research and experimental, $1.44 \%$ done, basic and applied research; $2.81 \%$

12th Education and Training in Optics and Photonics Conference, edited by

Manuel F. P. C. Martins Costa, Mourad Zghal, Proc. of SPIE Vol. 9289, 928927

(C) 2014 SPIE, OSA, IEEE, ICO · doi: 10.1117/12.2070724 
only makes experimental investigations; $2.53 \%$ only conducts investigations and $0.72 \%$ applied only performs basic research [18],[19].

Our country will soon join the free trade agreement with the U.S.A. or other countries and thus enter a range of materials and industry must have technology to establish a series of quality control in line with international standards. That is why we propose that optical inspection methods, technology enable the use of non-invasive, i.e., not through contact with the surface is completely clean and samples depending on its constitution can be reused [3], [4], [6], [8], [14], and [15]. Since 2009, I have been conducting research in the field of optical metrology and image processing, developing a model for the evaluation of surface roughness in the paper industry, based on texture analysis using co-occurrence matrix of gray levels [23], [24], [25], [26] industrial sectors. Wherefore are plans to extend the field of application to other materials, laminates specifically metallic and nonmetallic used in Panamenian Industry. Thus, organize and implement a research structure in surface characterization and evaluation of materials in the industrial sector, specifically in the manufacturing sector of plastics, wood, metal and others.

This means that conventional methods used in most cases, do not provide sufficient information about the structural and surface quality of the material to be inspected. Therefore, this proposal is to undertake basic and applied research in a topic of border handling the international scientific community, such as the speckle metrology area, in addition to digital image processing. Furthermore, the project will allow the formation of human resources in topic where the whole world is betting, mainly by large profits, at all levels, this implies and Panama cannot be the exception.

\section{DESCRIPTION OF PROJECT}

This project is part two strategic lines of the National Strategic Plan for Science and Technology in relation to the generation of knowledge, in this case in basic sciences, can be used as a tool to contribute to national development through research groups formally established and concrete results for surface characterization and evaluation of materials using optical metrology and digital image processing. The project also has an impact on the issue of the quality of industrial production, where the "National Strategic Plan for Science and Technology 2010-2014" [27] notes that Panama has traditionally been a technological structure that allow amendments and innovation in equipment and techniques used, which allow the investment recovers in less time, i.e. can improve our industrial weaknesses.

\subsection{Methodology}

2.1.1. Application of confocal microscopy method for measuring the roughness of the rolled material and non-metallic.

For the development of the methodology will make the following activities: These measures will be carried out in the laboratories of the company spin-off of CD6 SENSOFARTECH, Polytechnic University of Catalonia. Due to their accuracy and actual accuracy parameter measurements " $R_{a}$ " which provides the method, these will be taken as a yardstick to validate our proposed method. For this we plan to travel taking samples simultaneously characterize and concretize a collaboration agreement with the research center.

2.1.2. Texture analysis techniques of the images of the speckle patterns of laminates and non-metallic.

This project will use image processing techniques with second-order statistics, specifically the technique based on the cooccurrence matrix of gray levels (GLCM) [5], [12], [13], [17], [23], [24], [25], [26] ARMA (autoregressive movingaverage), Compressive Sensing [20], [21], [22]. Involves removing four GLCM textural descriptors capture a single image of the speckle pattern developed using the subjective speckle, i.e. speckle formation by an optical system [1], [2], [10], [11], [16]. With this setup you get the right size speckle pattern and to analyze the influence of: 
2.1 Angular variations of the incident light on the surfaces.

2.2 Changes in the wavelength of the illumination system.

2.3 Variations away from the lighting system.

2.4 Effect of the power of the lighting system.

2.5 Variations away from the capture system images to the samples.

To establish an objective comparison between different texture descriptors examined with optical methods used, were considered and measures used confocal microscopy method as our yardstick, which were taken as the dependent variable the simple linear regression model adopted for the comparison and validation of our proposed method and developed [20], [21], [22], [23], [24], [25], [26]. The coefficient of determination " $R^{2}$ " was the measure chosen to evaluate the fit of each method. In a linear regression model, the coefficient of determination is the percentage change in the dependent variable explained by the model. In other words, is a measure of the strength of the linear association between two variables $\mathrm{X}$ and $\mathrm{Y}$, in our case, confocal microscopy and analysis including texture respectively [26].

\section{RESULTS}

\subsection{Benefits and main beneficiaries}

Conduct basic and applied research in the field of inspection of materials will bring significant benefits to the near future. Since replacing equipment and methods that are currently used in industry, for other non-invasive, and whose speed of processing of information obtained faster, is a new challenge facing the Panamanian business sector for success in improving the product quality in this sense is to develop a "prototype" for the real time inspection in production lines. The main beneficiaries of this project will be the national and international scientific community, the country's productive sectors, Panamanian university students, where these issues can be included in the curricula of some careers, graduate level thesis. In the medium and long term, all that is developed in this project and others in the future, we predict that they will have a significant impact on the birth of some kind of technology company that is able to incubate in some of the business incubation systems that already exist in the country, with one of them at the Technological University of Panama.

\subsection{Expected Impact}

In addition to expanding our knowledge in the field and application of optical metrology and image processing, is to consolidate a national scientific structure in a way that improves the existing human resource training in using new methodology and development of new technological applications. With this project we interact directly with international scientists with vast experience in the area, which will help develop this subject nationally. It will also allow our researchers participate in international scientific activities, allowing you to create a culture of research, both basic and applied, more solid and robust. Therefore, this will help, no doubt, to encourage near future development and generation of proprietary technology, which is the basis for generating wealth, and thus progress through knowledge, support of current first world societies.

\section{CONCLUSIONS}

Perform a motivation campaign manager of the industrial establishments in order to achieve greater collaboration and more reliable information on this type of research. In which we mention, meetings with the most important groups such 
as Union of Industrialists of Panama, Panamanian Chamber of Commerce, Association of Small and Medium Enterprises, among others.

They have been shown to industries in Panama that processes optical inspection (optical metrology) and methods of digital image processing provide innovative solutions in the field of industrial automation processes which dramatically improves productivity and management the quality of manufactured products, thus increasing their competitiveness in the market. A large number of industrial activities have benefited from the use of these technologies, such as in the areas the production of paper, textiles, metal, glass, industrial machinery components, electronics manufacturing, pharmaceutical and medical among others.

\section{REFERENCES}

[1] Ersin Kayahan, Hasan Oktem, Fikret Hacizade, Humbat Nasibov, Ozcan Gundogdu, Measurement of surface roughness of metals using binary speckle image analysis, Tribology International Volume 43, Issues 1-2, JanuaryFebruary 2010, Pages 307-311.

[2] B. Dhanasekar, N. Krishna Mohan, Basanta Bhaduri, B. Ramamoorthy, Evaluation of surface roughness based on monochromatic speckle correlation using image processing, Precision Engineering Volume 32, Issue 3, July 2008, Pages 196-206.

[3] Ulf Persson, Surface roughness measurement on machined surfaces using angular speckle correlation, Journal of Materials Processing Technology Volume 180, Issues 1-3, 1 December 2006, Pages 233-238.

[4] R.J. Hocken, N. Chakraborty, C. Brown, Optical Metrology of Surfaces, CIRP Annals - Manufacturing Technology Volume 54, Issue 2, 2005, Pages 169-183.

[5] N.K Myshkin, A.Ya Grigoriev, S.A Chizhik, K.Y Choi, M.I Petrokovets, Surface roughness and texture analysis in microscale, Wear Volume 254, Issue 10, July 2003, Pages 1001-1009.

[6] H.Y Kim, Y.F Shen, J.H Ahn, Development of a surface roughness measurement system using reflected laser beam, Journal of Materials Processing Technology Volumes 130-131, 20 December 2002, Pages 662-667.

[7] B. Dhanasekar, B. Ramamoorthy, Restoration of blurred images for surface roughness evaluation using machine vision, Tribology International Volume 43, Issues 1-2, January-February 2010, Pages 268-276.

[8] Chih-Ming Liao, Ping S. Huang, Yi-Yuh Hwang, Ming Chen, Chung-Cheng Chiu, Robust technique of analyzing and locating laser speckle patterns for optical computer mice, Optics and Lasers in Engineering Volume 47, Issues 7-8, JulyAugust 2009, Pages 875-883.

[9] Richard K. Leach, CHAPTER 6 - Surface topography measurement instrumentation, Fundamental Principles of Engineering Nanometrology 2010, Pages 115-175.

[10] Anzar Alam, Jan Thim, Mattias O’Nils, Anatoliy Manuilskiy, Johan Lindgren, Joar Lidén, Online Surface Characterization of Paper and Paperboards in a Wide-range of the Spatial Wavelength Spectrum, Applied Surface Science Available online 2 May 2012.

[11] Pieter Samyn, Jürgen Van Erps, Hugo Thienpont, Gustaaf Schoukens, Paper coatings with multi-scale roughness evaluated at different sampling sizes, Applied Surface Science Volume 257, Issue 13, 15 April 2011, Pages 5613-5625.

[12] E.S. Gadelmawla, A vision system for surface roughness characterization using the gray level co-occurrence matrix, NDT \& E International Volume 37, Issue 7, October 2004, Pages 577-588.

[13] Ghassan A. Al-Kindi, Bijan Shirinzadeh, An evaluation of surface roughness parameters measurement using visionbased data, International Journal of Machine Tools and Manufacture Volume 47, Issues 3-4, March 2007, Pages 697708.

[14] E.S. Gadelmawla, M.M. Koura, T.M.A. Maksoud, I.M. Elewa, H.H. Soliman, Roughness parameters, Journal of Materials Processing Technology Volume 123, Issue 1, 10 April 2002, Pages 133-145. 
[15] Salim Hiziroglu, Shigehiko Suzuki, Evaluation of surface roughness of commercially manufactured particleboard and medium density fiberboard in Japan, Journal of Materials Processing Technology Volume 184, Issues 1-3, 12 April 2007, Pages 436-440.

[16] Xuezeng Zhao, Zhao Gao, Surface roughness measurement using spatial-average analysis of objective speckle pattern in specular direction, Optics and Lasers in Engineering Volume 47, Issue 11, November 2009, Pages 1307-1316.

[17] S. Dutta, A. Datta, N. Das Chakladar, S.K. Pal, S. Mukhopadhyay, R. Sen, Detection of tool condition from the turned surface images using an accurate grey level co-occurrence technique, Precision Engineering Volume 36, Issue 3, July 2012, Pages 458-466.

[18] Lugones, G., Mainieri, M., Encuesta de Innovación Tecnológica en la Industria Manufacturera. Experiencia de Panamá. Red de Indicadores de Ciencia y Tecnología Iberoamericana e Interamericana (RICYT); 2006.

[19] SENACYT, Encuesta de Investigación e Innovación en el Sector Privado de Panamá; 2008.

[20] Jianwei Ma, Compressed Sensing for Surface Characterization and Metrology. IEEE Transactions on Instrument and Measurement, 2010, 59 (6), 1600-1615.

[21] Candès, E.J., \& Wakin, M.B., An Introduction To Compressive Sampling, IEEE Signal Processing Magazine, V.21, March 2008.

[22] Merchan F. Nouvelles approaches de modelisation multidimennelle fondees sur la decomposition de Wold. Tesis doctoral, Universite de Bordeaux 1, 2009.

[23] Pino, A., Pladellorens, J., Cusola, O., Caum, J. "Roughness measurement of paper using speckle". Optical Engineering 50(9), 093605, 2011.

[24] Pino, A., Pladellorens, J., Colom, J.F., Cusola, O., Tosas, A.: "PAPERMAKING 7, Using laser speckle to measure the roughness of paper". The Paper and packaging industries technical resource. Tappi Journal, VOL. 10 NO. 3 (2011).

[25] Pino, A., Antó, J., Pladellorens, J.: "Determinación de propiedades superficiales del papel utilizando el análisis de la textura del patrón de speckle." Opt. Pura Apl. 43 (1) 43-48 (2010).

[26] Pino, A, Estudio y desarrollo de un método de análisis de las propiedades de lisura superficial de papeles especiales, utilizando el análisis de textura del patrón de speckle. Tesis doctoral, Universidad Politécnica de Catalunya, 2011.

[27] SENACYT, Plan Estratégico Nacional de Ciencia, Tecnología e Innovación de Panamá (PENCYT 20102014), 2010. 